\title{
APRENDIZAGEM COOPERATIVA COMO ESTRATÉGIA NO APRENDIZADO DE QUÍMICA NO ENSINO MÉDIO
}

\author{
Samuel Pedro Dantas Marques ${ }^{1}$, Fábio Nascimento Ávila ${ }^{2}$, \\ Francisco Audísio Dias Filho ${ }^{2}$, Maria Goretti Vasconcelos Silva ${ }^{2}$ \\ ${ }^{1}$ Instituto Federal de Educação, Ciência e Tecnologia do Rio Grande do Norte (IFRN) \\ ${ }^{2}$ Universidade Federal do Ceará \\ <samuelpdm@hotmail.com>, <fnascimentoavila@gmail.com>. \\ <audisio@ufc.br>, <mgvsilva@ufc.br>
}

DOI: $10.21439 /$ conexoes.v9i4.916

\begin{abstract}
Resumo. O presente trabalho apresenta o resultado da vivência de estudantes do ensino médio da cidade de Quixadá-CE com atividades de aprendizagem cooperativa aplicadas ao ensino de química. Quatro técnicas distintas de aprendizagem cooperativa (jigsaw, método dos pares, fila cooperativa e teste cooperativo) foram empregadas como estratégias de ensino-aprendizagem. Os resultados obtidos foram analisados no que diz respeito à apreensão dos conteúdos e observou-se um ambiente menos competitivo e mais colaborativo entre os estudantes, contribuindo assim para o desenvolvimento de aprendizagem significativa. O trabalho inclui descrição das técnicas de aprendizagem cooperativa, apresentação de todo o percurso metodológico utilizado, bem como a avaliação dos resultados.
\end{abstract}

Palavras-chaves: Aprendizagem cooperativa. Química. Soluções. Jigsaw.

Abstract. The present work shows the result of experiences of secondary school students from QuixadáCE city with activities of cooperative learning applied to the chemistry teaching. They were employed four techniques different from cooperative learning (jigsaw, pair methods, cooperative line, and cooperative test) as teaching and learning strategies. The results were analyzed with regard to seizures of contents and was observed a less competitive and more collaborative environment among students, thus contributing to the development of meaningful learning. The work includes a description of cooperative learning techniques, the presentation of all the methodological approach used, as well as evaluation of results.

Keywords: Cooperative learning. Chemistry. Solutions. Jigsaw.

\section{INTRODUÇÃO}

\subsection{O processo competitivo como forma de apren- dizagem}

O processo extremamente competitivo vivido pela sociedade atualmente se reflete no campo da educação que tem baseado os processos de ensino aprendizagem na competição e com abordagens pautadas na transferência mecânica e memorização dos conteúdos. Esse foco na competitividade pode representar um contra senso, já que o mercado de trabalho aponta a necessidade de formar profissionais com competência para o desenvolvimento de trabalhos em equipe. Vários autores criticam a escolha de abordagens exclusivamente conteudistas e competitivas no processo de ensino aprendizagem. utilização majoritária de uma metodologia tradicional, que privilegia de uma forma quase exclusiva, as aprendizagens conceptuais, conduz ao individualismo e à competição entre os alunos, reforça a exclusão social e os sentimentos de inadaptação dos que obtêm menor aproveitamento e não prepara os jovens para os desafios e as exigências atuais da sociedade. Ou seja, a aquisição pelos jovens de competências sociais não se coaduna com a utilização majoritária de atividades de aprendizagem que se enquadram numa metodologia tradicional (LOPES; SILVA 2009. p. 9) .

Estas abordagens baseadas prioritariamente na exposição e tendo a competitividade como fator motivador, consideram capazes aqueles que conseguem maior acúmulo de conteúdos e têm o professor como a figura central do processo de ensino aprendizagem, único detentor do conhecimento que deve transferir aos alu- 
nos que são considerados como uma folha em branco. Dessa forma, cria-se uma relação vertical e autoritária, portanto assimétrica do processo pedagógico o que não contribui para a formação de pessoas mais cooperativas e autônomas (FREIRE, 2004b). Ao mesmo tempo em que se revelam as limitações dos métodos tradicionais de ensino, diversos estudos vêm sendo produzidos no intuito de desenvolver estratégias pedagógicas onde os educandos se constituam como atores principais do seu processo de aprendizagem, propiciando o desenvolvimento da sua autonomia, além de maior eficiência no aprendizado conceitual e aplicabilidade nos desafios cotidianos considerando sua subjetividade.

No que se refere ao ensino de química, a experiência cotidiana tem revelado grandes desafios no que concerne ao ensino de algumas áreas específicas, como a físico-química onde as dificuldades de aprendizagem se expressam de forma mais nítida, induzindo em muitos casos, desinteresse ou mesmo rejeição acerca dos conceitos que englobam esta área (PINHEIRO; L; OLIVEIRA, 2010; UEHARA, 2005).

Buscar estratégias de ensino-aprendizagem que favoreçam a compreensão dos estudantes de ensino médio em várias áreas do conhecimento e sua aplicabilidade no cotidiano constitui-se um desafio importante para os pesquisadores da área de Ensino. Tomando-se como um exemplo exitoso, a experiência do Programa de Educação em Células Cooperativas (PRECE) no qual agricultores de uma pequena comunidade rural começaram a estudar em grupo numa casa de farinha para concluir seus estudos (fundamental e médio) e com o posterior ingresso de dois desses trabalhadores em cursos de graduação da UFC, delineou-se o que viria a se constituir um importante movimento no qual os primeiros a ingressar na universidade passaram a contribuir como educadores dos estudantes da comunidade que pleiteavam o seu ingresso no ensino superior. Este movimento solidário potencializou o ingresso de mais de 500 jovens daquela comunidade e de comunidades vizinhas em diversos cursos da UFC.

Do ponto de vista metodológico, naquele momento inicial os educadores apesar de trabalharem de forma cooperativa organizando-se em grupos que denominaram "células cooperativas", ainda não haviam entrado em contato com as técnicas e princípios da Abordagem Cooperativa em sala de aula sistematizada pelos irmãos norteamericanos David e Roger Johnson (JOHNSON; JOHNSON, 1975). Posteriormente o grupo de educadores do PRECE acessaram esse conjunto de conhecimentos incorporando-os ao processo pedagógico, ou melhor, tomando-o como base metodológica do PRECE que atualmente se constitui uma referência para for-

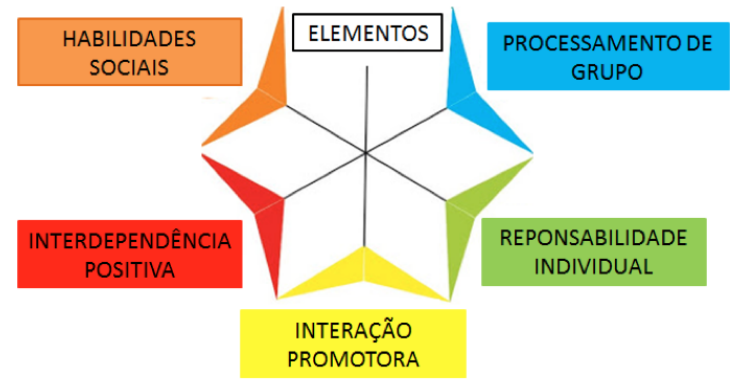

Figura 1: Elementos da aprendizagem cooperativa Fonte: Os autores, 2013.

mação de professores com essa abordagem no estado. Um dos resultados obtidos nesse percurso é em uma escola profissional situada no município de PentecostesCE cujo projeto político pedagógico (PPP) está totalmente ancorado nos princípios teóricos-metodológicos da aprendizagem cooperativa (AC) (PRECE, 2016).

\subsection{A aprendizagem cooperativa e seus elementos}

A AC é uma estratégia que pressupõe o aprendizado a partir de grupos constituídos tendo como premissas cinco elementos fundamentais: a interdependência positiva, a responsabilidade individual, a interação promotora (face a face), ênfase no ensino de habilidades sociais e o processamento de grupo (JOHNSON; JOHNSON 1989) que estão demonstrados na Figura 1.

A interdependência positiva é elemento fundamental para que se crie o ambiente de cooperação. O facilitador-educador deve preparar o material didático e o plano de aula de maneira que cada aluno dependa do outro para alcançar o objetivo final. Este objetivo é uma meta coletiva denominada critério de sucesso que ao ser atingido, possibilita uma espécie de bonificação do grupo. Este aspecto é planejado intencionalmente de maneira que todos os membros devam participar para que a tarefa seja completada. Existem diversos tipos de interdependência, que podem ser de metas, de materiais, de papéis e de identidade (KYNDT et al., 2013, MOTAEI, 2014).

Considerando que a meta coletiva só pode ser alcançada com o sucesso de todos do mesmo grupo é necessário a responsabilidade individual. Como os indivíduos são interdependentes é necessário que cada um seja responsável pela sua parte, caso um dos componentes do grupo não cumpra a sua meta individual, o grupo não atingirá seu objetivo coletivo. Busca-se com isso que os próprios estudantes se auto estimulem no processo de elaboração de suas tarefas individuais para depois partilhar de maneira adequada os seus conhe- 
cimentos com o grupo, bem como aprender os outros pontos com seus colegas (LOPES; SILVA, 2009, OXFORD, 1997).

Dois elementos da aprendizagem cooperativa caminham juntos. A interação promotora e as habilidades sociais. Dentro do processo grupal é fundamental que os alunos interajam discutindo olho no olho. A interação promotora ocorre quando os componentes estimulam uns aos outros a participar na execução das tarefas. Para que os estudantes superem todas as adversidades e conflitos de maneira construtiva gerados na discussão, precisam desenvolver as habilidades sociais. Alguns exemplos de habilidades sociais são: saber ouvir atentamente, esperar a vez de falar, criticar ideias e não pessoas, partilhar ideias, ajudar ao outro, etc. Estas habilidades são fundamentais para o processo grupal e a apreensão destas extrapola o processo de sala de aula possibilitando a formação de indivíduos mais críticos, ativos e engajados com a sociedade (FREIRE, 2004a; SILVA, 2008). O quinto elemento da aprendizagem cooperativa é um dos mais importantes: o processamento de grupo. Ao final de todo o processo o grupo deve se reunir para discutir o que aconteceu de positivo, negativo e propor ideias para maximizar o aprendizado. A principal finalidade do processamento é que se verifique quais as habilidades sociais que foram desenvolvidas e quais precisam ser mais trabalhadas para um máximo aproveitamento (JOHNSON; JOHNSON, 1989). Os autores deste trabalho relatam a seguir, atividades de aprendizagem cooperativa aplicadas ao ensino de química, utilizadas como estratégia de ensino-aprendizagem, contribuindo assim para o desenvolvimento de uma aprendizagem significativa e o desenvolvimento de habilidades individuais e em grupo dos educandos.

\section{METODOLOGIA}

Foram desenvolvidos instrumentos pedagógicos contendo os elementos fundamentais desta abordagem (planos de aula e materiais didáticos) a serem aplicados durante o primeiro bimestre de 2013 no estudo das soluções com 50 estudantes do $2^{\circ}$ e $3^{\circ}$ ano do ensino médio da escola privada Colégio Amadeu Cláudio Damasceno, localizada no município de Quixadá-CE cuja proposta pedagógica baseia-se na competitividade e transmissão de conhecimentos.

O percurso metodológico utilizado para a produção deste trabalho iniciou-se pela produção dos instrumentos pedagógicos, durante curso de formação em aprendizagem cooperativa oferecido pelo PRECE (planos de aula e materiais didáticos). Posteriormente realizou-se oficinas de formação em AC para os estudantes envolvidos nesta pesquisa, durante uma semana em horário extracurricular. Ao final das oficinas, os estudantes responderam ao $1^{\circ}$ instrumento de avaliação, na forma de questionário (contendo questões objetivas e discurssivas), com o intuito de verificar o conhecimento prévio dos mesmos acerca de trabalhos em grupo. Somente após as oficinas de formação em AC, as aulas foram ministradas, e em sequência, realizadas as análises em grupo e individual sobre as técnicas utilizadas, com a aplicação do $2^{\circ}$ instrumento de avaliação também sob formato de questionário e a realização de um círculo de cultura. Portanto a análise do processo de aprendizagem com as técnicas utilizadas, foi realizada a partir de três abordagens: aplicação de instrumentos de avaliação sob o formato de questionários (anônimos) com questões subjetivas e objetivas, observação participante e realização de um círculo de cultura.

\subsection{Conteúdos abordados}

As aulas utilizando técnicas de AC foram planejadas com atividades de 100 minutos ( $2 \mathrm{~h} / \mathrm{a}$ ) contendo os seguintes subtemas referentes ao tema "estudo das soluções" na disciplina de físico-química:

- Principais tipos de dispersões, características, propriedades e aplicações;

- Introdução ao estudo das soluções (propriedades e classificações);

- Coeficiente de solubilidade de sólidos em água, suas relações matemáticas e aplicações no cotidiano;

- Tipos de solubilidade e solubilidade gasosa (demonstração e aplicações da lei de Henry);

- Relações quantitativas entre soluto e solvente (unidades de concentração);

- Diluição, mistura de soluções e titulação;

- Propriedades coligativas.

Para cada subtema foi elaborado um material didático, contendo informações teóricas e exercícios avaliativos, incluindo as habilidades e competências exigidas pelo ENEM sobre o conteúdo mencionado. As aulas se realizaram em 16 encontros durante o primeiro bimestre de 2013. Antes do início dos encontros as salas eram devidamente preparadas para garantir que os tempos previstos nos planos de aula fossem atingidos, bem como a formação dos grupos foi previamente estabelecida pelo professor-facilitador visando garantir a heterogeneidade dos mesmos. 


\subsection{Técnicas de aprendizagem cooperativa utiliza- das}

A escolha das técnicas se fez com referência no estudo bibliográfico e análise daquelas que mais se adequaram à temática e ao contexto do estudo. A pesquisa bibliográfica revela que os métodos cooperativos, quando bem empregados, podem favorecer o processo de aprendizagem (BARBOSA; JÓFILI 2004, LOPES; SILVA 2009; SENGUL; KATRANCI, 2014a).

Aronson e colaboradores (1978) desenvolveram um método de ensino que dialoga diretamente com os elementos da AC, denominado Jigsaw (JS) ou quebra cabeças sistematizado, com processos específicos e particularmente adequados ao desenvolvimento de competências cognitivas (EVCIM; IPEK, 2013; BUHR et al., 2014). Foram utilizadas quatro técnicas distintas de AC na elaboração dos instrumentos pedagógicos: Método Jigsaw (JS), Método dos Pares (MP), Fila Cooperativa (FC) e Teste Cooperativo (TC) adaptados a partir de diversas referências estudadas (LOPES; SILVA, 2009 FATARELI et al. 2010; BUHR; HEFLIN; WHITE 2014).

O JS consiste em fragmentar um tema principal em tópicos. Os educandos são inicialmente organizados em grupos de base nos quais cada um recebe um dos tópicos preparados e faz a leitura individual. Após a leitura o educando segue para outro grupo denominado grupo de peritos, constituído de educandos com o mesmo tópico. O objetivo deste grupo é aprofundar a discussão sobre este tópico. Posteriormente, cada participante retorna ao grupo base e compartilha seu aprendizado, passando a ter conhecimento de todos os tópicos. Ao final realiza-se, uma avaliação escrita individual, a partir da qual objetiva-se obter o critério de sucesso da atividade que é uma meta coletiva com relação ao grupo de base, previamente definida. A Figura 2a demonstra de maneira simplificada o processo.

Pesquisa bibliográfica revela que este método é um dos mais utilizados pois, propicia a produção de um conhecimento mais aprimorado, porém sua utilização para estudos com química ainda é recente e existem poucos trabalhos publicados na literatura (BARBOSA; JÓFILI 2004; FATARELI et al., 2010; EVCIM; IPEK, 2013. LEITE et al., 2013; SENGUL; KATRANCI, 2014b BUHR; HEFLIN; WHITE, 2014).

O método dos pares consiste na formação de duplas (fig. 2b). Cada componente da dupla recebe um dos dois materiais didáticos diferentes e intercomplementares preparados pelo facilitador. Os estudantes devem realizar a leitura individual de seu tópico, anotar os tópicos mais significativos e em seguida deve explicá-lo ao outro componente da dupla e realizar uma discussão acerca do conteúdo. O mesmo ocorrerá com o outro componente da dupla. Assim após as leituras, explicações e discussões, a dupla realiza um teste escrito em conjunto contendo questões estilo ENEM sobre os dois tópicos abordados no processo. Após o teste em conjunto os pares são desfeitos e os mesmos realizam uma nova avaliação, sendo que desta vez realizada individualmente com questões diferentes das iniciais, porém contendo os mesmos assuntos abordados, sendo esta avaliação o critério de sucesso desta atividade (BARBOSA; JÓFILI, 2004; LOPES; SILVA, 2009).

O método da fila cooperativa visa alternar os temas estudados em fileiras onde os alunos possuem tópicos distintos e vão construir justificativas para compartilhar uns com os outros e pode ser considerado uma junção do Jigsaw com o método dos pares já que usa a estratégia de fragmentação do conteúdo e promove a interação promotora aos pares conforme demonstra a Figura 2c. Os integrantes da fila (A) permanecem sempre fixos enquanto os integrantes da fila (B) se alternam no sentido horário até que o ciclo se complete. Após as discussões realizam uma atividade avaliativa com uma meta coletiva sobre todos os temas abordados.

O método do teste cooperativo consiste numa técnica em que a importância do trabalho em grupo é enaltecida a cada etapa que o método é desenvolvido. No primeiro momento, o estudante executa a tarefa individualmente. Cada estudante tenta resolver cinco questões e entrega o gabarito ao professor. Essa etapa está ilustrada como Avaliação Individual 1(fig. 2d). Em seguida, os estudantes formam grupos de cinco integrantes. Nesse momento cada estudante traz consigo as cinco questões do momento anterior o que significa que ao todo o grupo tem vinte e cinco questões para resolver. A tarefa de resolução das questões é feita em coletivo e ao final um novo gabarito é entregue ao professor. Essa etapa está ilustrada como Avaliação em Grupo (fig. 2d). Por fim, o professor promove o fechamento da aula explicando cada questão e finaliza a atividade solicitando que os estudantes resolvam, individualmente, três questões diferentes das discutidas. O gabarito deve ser entregue ao professor. Essa última etapa está contemplada como Avaliação Individual 2 (fig. 2d).

Segundo as técnicas cooperativas estudadas, a heterogeneidade dos grupos é uma característica fundamental. Dessa maneira, em todas as técnicas utilizadas os alunos foram agrupados de forma a incluir no mesmo grupo os mais diferentes perfis. Para a aplicação das técnicas de AC, a ambiência é um fator importante. Neste sentido, antes do início das aulas as cadeiras foram posicionadas de forma a possibilitar a efetivação das aulas segundo o tempo sugerido nos referidos pla- 


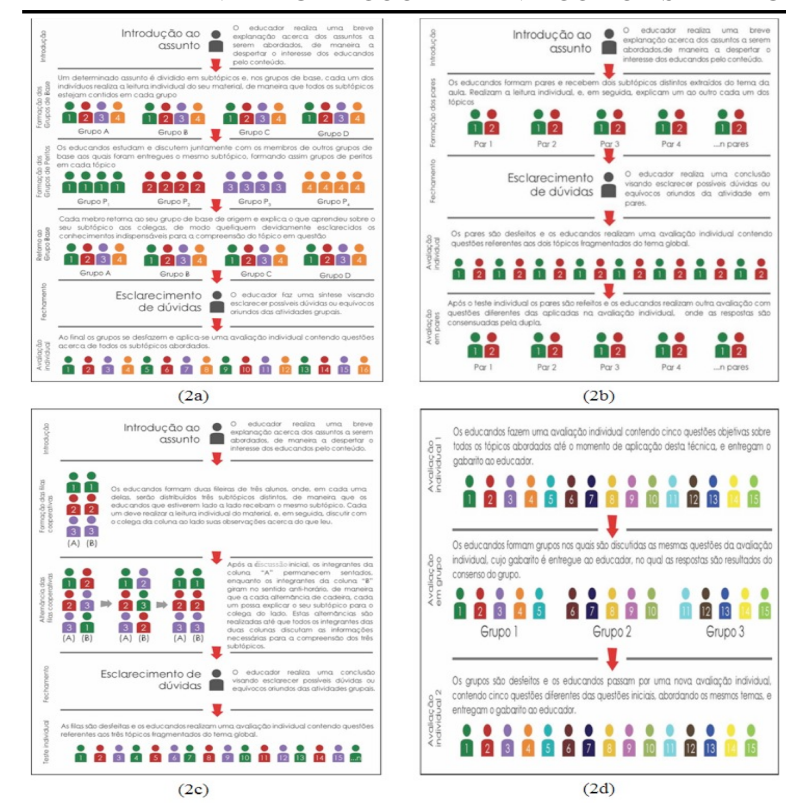

Figura 2: Representação esquemática do Método JigSaw (2a), Método dos Pares (2b), Fila Cooperativa (2c) e Teste Cooperativo (2d).

nos de aula.

\subsection{Instrumentos de avaliação}

A análise do processo de aprendizagem com as técnicas utilizadas, bem como o rendimento escolar foi realizada a partir de três abordagens: instrumentos de avaliação sob o formato de questionários, realização de um círculo de cultura e a observação participante.

Foram produzidos dois diferentes tipos de questionários: o primeiro com questões subjetivas e objetivas acerca dos assuntos estudados, visando verificar a apreensão dos conteúdos e outros dois buscando identificar a percepção dos estudantes no que se refere à vivência do aprendizado utilizando técnicas de AC.

Os círculos de cultura sistematizados por Freire (1996) propõem uma aprendizagem que rompe com a fragmentação e exige uma tomada de posição frente às situações vivenciadas em determinados contextos. Esta abordagem está em consonância com os princípios da aprendizagem cooperativa, que visa à formação de estudantes protagonistas do seu processo de aprendizagem.

Os círculos de cultura estruturam-se em quatro momentos distintos: a investigação do universo vocabular, do qual são extraídas palavras geradoras, cujo objetivo é realizar uma primeira leitura da realidade, ajudando o educador a interagir com o educando para que possa emergir o tema gerador. Outro momento é a tematização, ou seja, processo no qual os temas são decodificados com o intuito de despertar a consciência do vi- vido, o seu significado social, promovendo a ampliação do conhecimento e a compreensão dos educandos sobre a própria realidade, na perspectiva de intervir criticamente sobre ela. Por fim, ocorre a problematização que busca superar a visão ingênua a partir da observação da realidade com todas as suas contradições, buscando explicações que o ajudem a transformá-la (DANTAS. 2010). No contexto deste estudo buscou-se, com o círculo de cultura, observar e identificar aspectos significativos para os estudantes envolvidos, em relação ao processo de aprendizagem com a abordagem cooperativa e, com base na problematização, estabelecer parâmetros de análise da apreensão dos conteúdos com a abordagem cooperativa em relação às técnicas usualmente utilizadas na escola de origem (MARQUES, 2013).

\section{RESULTADOS E DISCUSSÕES}

\subsection{O saber prévio do estudante acerca de aborda- gens grupais no processo de aprendizagem}

A análise do instrumento, sob forma de questionário, aplicado previamente com os estudantes para apreender sua experiência com abordagens de grupos, revelou que $100 \%$ destes tinham alguma experiência com este tipo de abordagem. A análise revela ainda que para $80 \%$ dos estudantes o ambiente escolar foi o único cenário de vivência grupal e apenas $20 \%$ referiu-se a espaços religiosos, grupo de jovens e musicais como cenários dessas vivências. O gráfico (3a) mostra que para a maioria dos estudantes, essas atividades ocorrem com frequência ocasional ou rara, o que parece indicar que nesta instituição de ensino este tipo de abordagem é pouco enfatizada e a metodologia tradicional parece constituir-se o principal caminho pedagógico adotado.

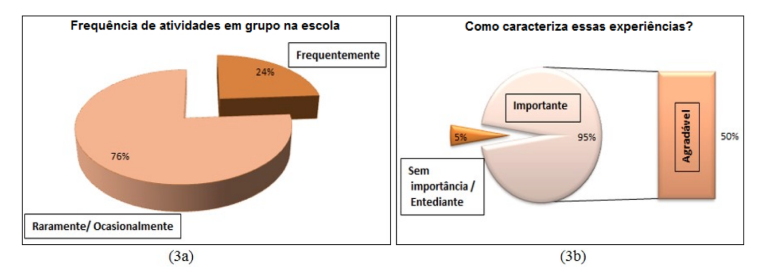

Figura 3: Análise do saber prévio dos educandos com atividades grupais (3a) realização de trabalhos em grupo na escola (3b) importância atribuída. Fonte: Os autores, 2013.

O resultado indica ainda que $95 \%$ dos participantes (gráfico 3b), já referenciam o trabalho em grupo como algo significativo e importante apesar da sua reduzida aplicação, sendo que para a 50\% dos estudantes essas atividades produzem um ambiente agradável em sala de aula. Outro questionamento realizado a partir do questionário diz respeito às potencialidades do trabalho 
em grupo como técnica de aprendizagem e socialização. Neste sentido os estudantes apontaram vários aspectos:

\begin{abstract}
"vivenciar as individualidades e lidar com a diversidade; aprender a trabalhar em grupo; trabalho mais aberto; socialização; aprimoramento que possibilita maior índice de entendimento; interativo; compartilhar conhecimentos; desenvolver ideias coletivas."
\end{abstract}

Ao mesmo tempo apontam desafios como:

\begin{abstract}
"a dificuldade de alguns para organizar as ideias; nem todos colaboram; dificuldade do consenso entre todos; a timidez de alguns e o egoísmo de outros; a divisão igualitária das tarefas; a ocorrência de desavenças; a necessidade de conciliação entre opiniões opostas."
\end{abstract}

A análise das opiniões dos educandos possibilita a reflexão de que a referência dos estudantes sobre a abordagem grupal no que diz respeito aos desafios coincide com as características do trabalho em grupos não estruturados (grupos tradicionais). Ao mesmo tempo as potencialidades e características apontadas por eles coincidem em sua maioria com elementos da $\mathrm{AC}$ que ainda não conheciam. A aplicação de técnicas cooperativas pode promover habilidades importantes para experiências em equipe (MENEZES; BARBOSA; JóFILI 2007).

Apesar de, em sua grande maioria (95\%), referenciarem o trabalho em grupo como algo significativo, paradoxalmente referenciam a competitividade como algo importante para o processo de ensino aprendizagem. Estas impressões refletem o investimento por parte da escola, em torno de atividades pedagógicas baseadas na competição.

Como forma de traçar um perfil de sociabilidade dos educandos, foram utilizados testes nos quais os mesmos identificam aqueles que desejam ter como parceiros para o trabalho em grupo. A análise destes instrumentos revelou que os estudantes identificam como principais parceiros os colegas que cotidianamente expressam maior capacidade cognitiva. Este resultado aliado a observação participante do autor por três anos consecutivos, foram reveladores da necessidade de buscar garantir a heterogeneidade dos grupos, distribuindo os educandos identificados pela maioria nos diversos grupos.

\subsection{Análise das avaliações escritas relativa ao aprendizado com as técnicas cooperativas}

Os resultados das avaliações escritas individuais e coletivas estão descritas para cada um dos métodos utilizados e apresentados sequencialmente levando em consideração o número de vezes que foi utilizada e a ordem de aplicação dos assuntos. São apresentados os percentuais de acerto das avaliações individuais ou em grupo, bem como o percentual de grupos que atingiram os critérios de sucesso por atividade.

\subsubsection{Análise do aprendizado com a técnica JIG- SAW}

A escolha desta técnica para esta pesquisa se deu pelo fato de propiciar a exposição sobre os assuntos a partir de vários pontos de vista, considerando que o educando participa de dois grupos diferentes. A análise dos vários estudos consultados acerca da AC revela ser o JS a técnica comumente mais utilizada em salas de aula, que trabalham com AC. Neste estudo ela foi utilizada em quatro momentos. No primeiro momento a temática estudada tratou dos principais tipos de dispersões, características, propriedades e aplicações.

$\mathrm{O}$ instrumento avaliativo utilizado revelou neste primeiro momento que no critério individual $64,7 \%$ dos estudantes obtiveram aproveitamento igual ou superior a média escolar (nota 6,0) conforme evidencia a Figura 4a. Nesta atividade apenas $40 \%$ dos grupos atingiram o critério de sucesso, o que pode ser justificado pela inexperiência dos educandos com essa abordagem.

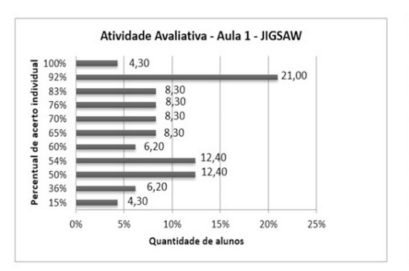

(4a)

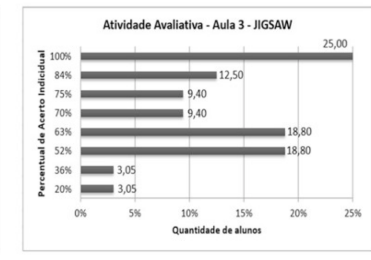

(4b)
Figura 4: Percentuais de acerto individual aula 1 (4a). Percentuais de acerto individual aula 3 (4b) Fonte: Os autores, 2013.

O segundo momento no qual esta técnica foi utilizada contemplou a abordagem dos seguintes conteúdos: coeficiente de solubilidade de sólidos em água, suas relações matemáticas e aplicações no cotidiano. Em relação a este tema a atividade avaliativa (4b) revelou que $75,1 \%$ dos estudantes tiveram um percentual de acerto individual acima da média escolar enquanto o critério de sucesso coletivo desta atividade foi atingido por $60,0 \%$ dos grupos.

Os resultados da análise da aplicação desta técnica para o conteúdo "unidades de concentração"são apresentados na Figura 5. Os resultados revelaram um percentual de acerto individual de apenas $42,5 \%$ dos estudantes acima da média escolar (5a) e que $57,5 \%$ dos grupos atingiram a meta coletiva. Uma das questões referidas pelos estudantes como desafiadora em relação a este tema diz respeito ao fato deste conteúdo exigir 


\section{APRENDIZAGEM COOPERATIVA COMO ESTRATÉGIA NO APRENDIZADO DE QUÍMICA NO ENSINO MÉDIO}

exaustivo raciocínio matemático com um tempo considerado por eles insuficiente.

Por fim, no quarto momento em que o jigsaw foi utilizado, abordou-se o estudo das propriedades coligativas (crioscopia, tonoscopia, ebulioscopia e osmometria). Este foi também ainda o momento final de utilização das técnicas cooperativas com o grupo. A atividade avaliativa demonstrou que $81,6 \%$ dos estudantes obtiveram notas individuais acima da média escolar (gráfico $5 b)$ e que o critério de sucesso foi alcançado por $80 \%$ dos grupos, apesar de ser este um tema que também envolve raciocínio matemático.

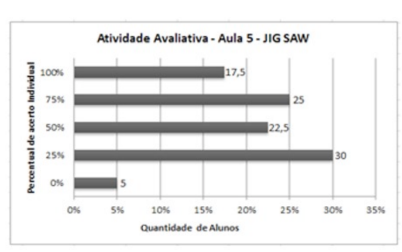

(5a)

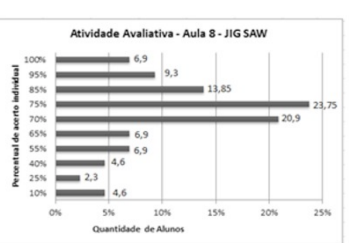

(5b)
Figura 5: Percentuais de acerto individual aula-5 (5a). Percentuais de acerto individual aula-8 (5b) Fonte: Os autores, 2013.

A Figura 6 demonstra a evolução dos acertos individuas nas aulas utilizando Jigsaw (6a). É possível observar que com exceção da aula 5, obteve-se um aumento sequencial do número de estudantes com nota cima da média escolar.

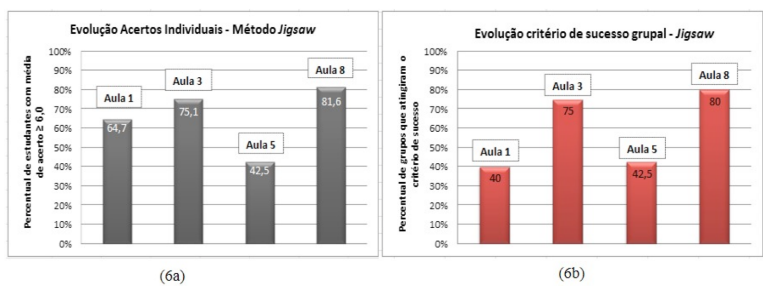

Figura 6: Evolução dos percentuais de acerto individual (6a). Evolução de obtenção do critério de sucesso grupal (6b) Fonte: Os autores, 2013.

A Figura 6 b indica que os critérios de sucesso grupal seguiram uma sequencia semelhante à das notas individuais, ou seja, à medida que as atividades iam se sucedendo o número de grupos que conseguiam atingir o critério de sucesso também aumentava. Este resultado corrobora com a ideia de processualidade do aprendizado com este tipo de abordagem. Uma tendência de crescimento no percentual de acertos em ambas situações foi observada (fig. 7). Porém, a velocidade para os grupos é maior. Isso sugere que com o tempo os estudantes passam a trabalhar juntos de maneira mais efetiva diminuindo o tempo de aprendizado entre aqueles mais preparados e os com maior dificuldade. Os dados obtidos com a utilização desta técnica estão de acordo com pesquisa realizada por Fatareli et al. (2010) no qual verificou-se crescente elevação dos acertos individuais e grupais a medida que as atividades com AC se sucediam devido a internalização e familiarização dos procedimentos por parte dos estudantes.

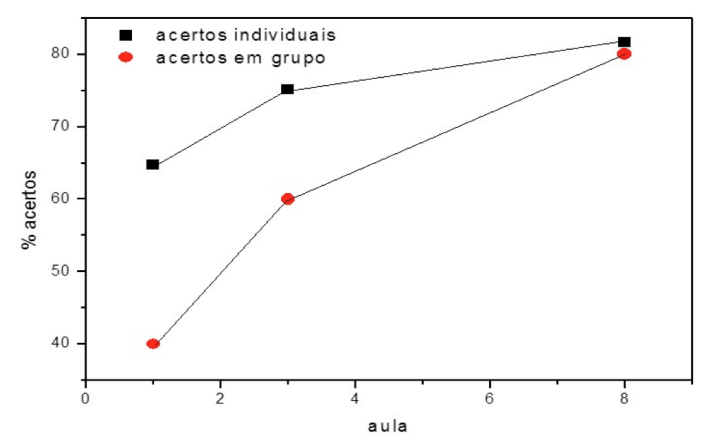

Figura 7: Tendência de crescimento de acertos individual e grupal. Fonte: Os autores, 2013

\subsubsection{Análise do aprendizado com o Método dos Pares}

Esta técnica foi utilizada em apenas um momento e a temática abordada foi o estudo das propriedades das soluções e uma introdução ao conceito de coeficiente de solubilidade. Este foi o segundo momento de contato dos estudantes com as técnicas de AC. A análise dos resultados individuais indicam que $70 \%$ dos estudantes obtiveram média igual ou superior a média escolar (fig. 8a). Com a utilização da avaliação em pares houve um alcance de $96,0 \%$ igual ou superior a média escolar (8b). No entanto, o critério de sucesso teve um alcance de apenas $60,0 \%$. Apesar de ter sido utilizada por uma única vez fica evidenciado que é uma técnica de $\mathrm{AC}$ que possibilita aos estudantes se tornarem professores dos seus colegas e conduz a que aprendam tanto como aqueles a quem ensinam conforme relatado por Lopes e Silva (2009). Os educandos indicaram nos questionários que sentem-se mais a vontade em aprender com seus colegas devido sua maior proximidade.

\subsubsection{Análise do aprendizado com o Teste Coope- rativo}

Esta técnica foi utilizada em três momentos com a finalidade de revisar os conteúdos. No primeiro momento os conteúdos revisados (aula 4) foram relativos ao estudo das dispersões, soluções verdadeiras, coeficiente de solubilidade, soluções supersaturadas, tipos de dissolução e solubilidade gasosa. Com relação à 


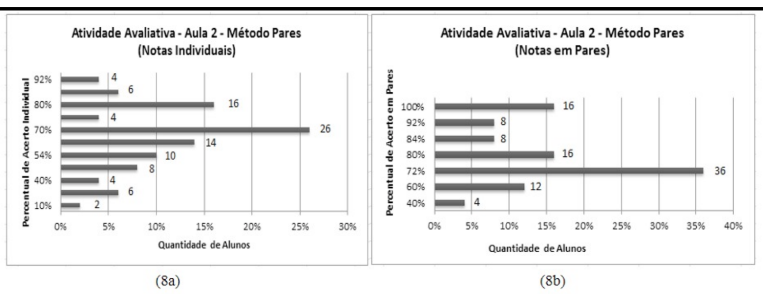

Figura 8: Percentuais de acerto nota individual (8a). Percentual de acerto nota em pares (8b) Fonte: Os autores, 2013.

análise das atividades avaliativas individuais realizadas observou-se que $64,2 \%$ dos educandos obtiveram notas iguais ou superiores a média escolar. Quando as resoluções das mesmas questões realizadas individualmente realizadas em grupo, todos conseguiram acertar $100,0 \%$ das questões. Na segunda atividade avaliativa individual realizada após a discussão grupal verifica-se que $77,0 \%$ conseguiram notas com valores iguais ou superiores a média escolar, que representa um aumento de $12,8 \%$ com relação a primeira avaliação individual.

Os assuntos revisados durante a segunda atividade com o teste cooperativo envolveram as relações quantitativas entre soluto e solvente (unidades de concentração). A análise das atividades avaliativas individuais realizadas mostrou que $73,7 \%$ dos estudantes conseguiram atingir notas iguais ou superiores à média escolar, representando um aumento de $9,6 \%$ do resultado com o teste cooperativo na primeira atividade individual. Ao resolverem as mesmas questões em grupo esse resultado se elevou para 94,0\%. Na realização do segundo teste individual $94 \%$ dos alunos conseguiram obter o critério de sucesso nas questões propostas na atividade.

No terceiro e último momento que foi utilizado o teste cooperativo foram revisados todos os assuntos abordados durante as aulas com AC. Mediante análise é possível observar, em todos os casos com o teste cooperativo, que o índice de acerto aumenta significativamente após a resolução em grupo em todos os momentos. Os percentuais de acerto em grupo e individual permaneceram inalterados com relação ao encontro anterior.

A Figura 9 apresenta os resultados acima mencionados e revela que nos três momentos em que o Teste Cooperativo foi usado, os percentuais de acerto aumentaram após a resolução dos problemas em grupo e que após esta resolução, os acertos individuais também aumentam se comparados ao primeiro teste individual, ressaltando que, no segundo momento, as questões individuais são diferentes das trabalhadas anteriormente.

A análise desses resultados permite inferir que o teste cooperativo é uma ferramenta importante em ati-

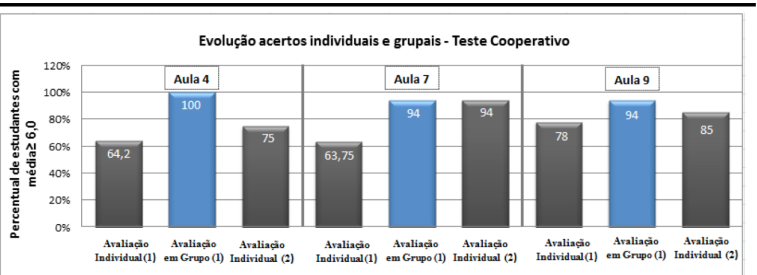

Figura 9: Evolução dos resultados obtidos com a aplicação do teste cooperativo. Fonte: Os autores, 2013.

vidades de revisão, considerando que em todos os momentos nos quais essa técnica foi utilizada ocorreu aumento dos percentuais de acerto. Segundo a figura acima o percentual de aumento se acentua nas atividades em grupo, nas quais os estudantes, via de regra, conseguiram de forma compartilhada resolver todas as questões. $\mathrm{O}$ aprendizado em sua dimensão cognitiva se explicita também nos índices crescentes de acerto individual após a discussão grupal. As vantagens desta técnica também se estendem às dimensões subjetivas, pelo fato de produzir um clima de descontração, participação e complementariedade entre os estudantes e entre estes e o professor. Portanto trata-se de uma ferramenta importante para promover integração e bons resultados cognitivos aos estudantes. Verifica-se nesta atividade um dos elementos da AC que é a interação promotora, tendo em vista que a cada atividade realizada, os estudantes juntos, conseguem apreender mais facilmente os conteúdos. Este crescimento deve-se também em grande parte ao aprimoramento das relações que ocorrem durante o processamento de grupo, no qual os educandos discutem questões com a finalidade de dinamizar as relações entre os mesmos a partir da superação de seus conflitos (LAAL, 2013; JOHNSON; JOHNSON, 1992).

\subsubsection{Análise do aprendizado com a técnica da Fila Cooperativa}

Esta técnica também foi utilizada em apenas um momento cuja temática versou sobre o processo de diluição e misturas de soluções. A motivação para escolha desta técnica foi a possibilidade de ampliar as opções metodológicas aplicáveis a assuntos que envolvam lógica matemática. A atividade avaliativa revelou que $63,9 \%$ dos estudantes conseguiram realizar todas as três questões propostas e que os demais conseguiram obter dois acertos dos três possíveis; assim, todos os grupos alcançaram o critério de sucesso. Uma questão importante em relação à temática abordada e que a mesma também está relacionada com aspectos matemáticos. $\mathrm{O}$ sucesso da aprendizagem com esta técnica evidencia a 
APRENDIZAGEM COOPERATIVA COMO ESTRATÉGIA NO APRENDIZADO DE QUÍMICA NO ENSINO MÉDIO

potencialidade da mesma para assuntos desta natureza e demonstra que a utilização da AC aplica-se a todos os tipos de conteúdos, desde assuntos que envolvem a subjetividade dos estudantes (conceitos teóricos) bem como aqueles relacionados a raciocínio lógico e algébrico.

\section{CONSIDERAÇÕES FINAIS}

Diante das reflexões produzidas, pode-se considerar a importância de se trabalhar propostas pedagógicas ativas e problematizadoras, potencializadoras do protagonismo estudantil, como forma de superação das dificuldades de aprendizagem historicamente evidenciadas na apreensão de conteúdos em disciplinas como a Química.

Dessa forma, a AC se confirma como estratégia exitosa na aprendizagem do ensino de química, como também na construção de relações cooperativas, favorecendo a formação integral do educando e incentivando o protagonismo estudantil.

\section{REFERÊNCIAS}

BARBOSA, R. M. N.; JÓFILI, Z. M. S. Aprendizagem cooperativa e ensino de química - parceria que dá certo. Ciência \& Educação, v. 10, n. 1, p. 55 - 61, 2004.

BUHR, G. T.; HEFLIN, M. T.; WHITE, H. K. Using the jigsaw cooperative learning method to teach medical students about long-term and postacute care. Journal of the American Medical Directors Association, v. 15, n. 6, p. 429-434, 2014.

DANTAS, V. L. A. Dialogismo e arte na gestão em saúde: a perspectiva popular nas cirandas da vida em Fortaleza-CE. Tese (Doutorado) — Faculdade de Educação, Universidade Federal do Ceará, Fortaleza, 2010.

EVCIM, H.; IPEK, O. F. Effects of jigsaw ii on academic achievement in english prep classes. Procedia-Social and Behavioral Sciences, v. 70, p. 1651-1659, 2013.

FATARELI, E. F.; FERREIRA, L. N. A.; FERREIRA, J. Q.; QUEIROZ, S. L. Método cooperativo de aprendizagem jigsaw no ensino de cinética química. Química Nova na Escola, v. 32, n. 3, p. 161-168, 2010.

FREIRE, P. Educação como prática de liberdade. 20. ed. Rio de Janeiro: Paz e Terra, 1996.

Pedagogia da Autonomia: saberes necessários à prática educativa. 33. ed. São Paulo: Paz e Terra, 2004a.
. Pedagogia do oprimido. 38. ed. Rio de Janeiro:

Paz e Terra, 2004b.

JOHNSON, D. W.; JOHNSON, R. T. Learning together and alone: cooperative, competitive, and individualistic learning. 1. ed. Boston: Allyn \& Bacon, 1975.

Leading the cooperative school. [S.1.]: Edina, $\mathrm{MN}$ : Interaction Book Company, 1989.

Implementing cooperative learning.

Contemporary Education, v. 63, n. 3, p. 173-180, 1992.

KYNDT, E.; RAES, E.; LISMONT, B.; TIMMERS, F.; CASCALLAR, E.; DOCHY, F. A meta-analysis of the effects of face-to-face cooperative learning. do recent studies falsify or verify earlier findings? Educational Research Review, v. 10, p. 133-149, 2013.

LAAL, M. Collaborative learning; elements. Procedia Social and Behavioral Sciences, v. 83, p. 814-818, 2013.

LEITE, I. S.; LOURENçO, A. B.; LICIO, J. G.; HERNANDES, A. C. Uso do método cooperativo de aprendizagem jigsaw adaptado ao ensino de nanociência e nanotecnologia. Revista Brasileira de Ensino de Física, scielo, v. 35, p. 1 - 7, 12 2013. ISSN 1806-1117. Disponível em: $<$ http://www.scielo.br/scielo.php?script=sci_arttext\& pid=S1806-11172013000400015\&nrm=iso $>$

LOPES, J.; SILVA, H. S. Aprendizagem cooperativa na sala de aula: um guia prático para o professor. 2 . ed. Lisboa: Lidel, 2009.

MARQUES, S. P. D. aprendizagem cooperativa como possibilidade de superação das dificuldades no aprendizado da química: o olhar dos educandos no ensino médio. Dissertação (Mestrado) — Universidade Federal do Ceará, Fortaleza, Fortaleza, 2013.

MENEZES, M. G.; BARBOSA, R. M. N.; JóFILI, Z. M. S. Aprendizagem cooperativa: o que pensam os estudantes? Linguagens, Educação e Sociedade, v. 17, p. 51-62, 2007.

MOTAEI, B. On the effect of cooperative learning on general english achievement of kermanshah islamic azad university students. Procedia - Social and Behavioral Sciences, v. 98, p. 1249-1254, 2014.

OXFORD, R. L. Cooperative learning, collaborative learning, and interaction: three communicative strands 
in the language classroom. The Modern Language Journal, v. 81, n. 4, p. 443-456, 1997.

PINHEIRO, A. N.; L, M. E.; OLIVEIRA, A. C. Estudo de casos na formação de professores de química. Química Nova, v. 33, n. 9, p. 1996-2002, 2010.

PRECE. Programa de Aprendizagem Cooperativa em Células Estudantis. 2016. Disponível em: $<$ http://www.prece.ufc.br/> Acesso em: março de 2016.

SENGUL, S.; KATRANCI, Y. Effects of jigsaw technique on mathematics self-efficacy perceptions of seventh grade primary school students. Procedia Social and Behavioral Sciences, v. 116, p. 333-338, 2014.

Effects of jigsaw technique on mathematics self-efficacy perceptions of seventh grade primary school students. Procedia - Social and Behavioral Sciences, v. 116, p. 339-344, 2014.

SILVA, A. J. Aprendizagem cooperativa no ensino de química: uma proposta de abordagem em sala de aula. Dissertação (Mestrado) — Institutos de Física e Química, Universidade de Brasília, 2008.

UEHARA, F. M. G. Refletindo dificuldades de aprendizagem de alunos do ensino médio no estudo do equilíbrio químico. Dissertação (Mestrado) Universidade Federal do Rio Grande do Norte, 2005. 